Sport, Education and Society

\title{
Bodies in the early childhood education classroom: a Bourdieusian analysis of curricular materials
}

Vladimir E. Martínez-Bello, Yolanda Cabrera García-Ochoa, José DíazBarahona \& María del Mar Bernabé-Villodre

To cite this article: Vladimir E. Martínez-Bello, Yolanda Cabrera García-Ochoa, José DíazBarahona \& María del Mar Bernabé-Villodre (2019): Bodies in the early childhood education classroom: a Bourdieusian analysis of curricular materials, Sport, Education and Society, DOI: 10.1080/13573322.2019.1690442

To link to this article: https://doi.org/10.1080/13573322.2019.1690442

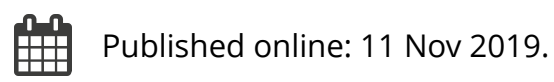

Submit your article to this journal $\widetilde{ }$

III Article views: 39

Q View related articles $\sqsubset$

View Crossmark data \lceil 


\title{
Bodies in the early childhood education classroom: a Bourdieusian analysis of curricular materials
}

\author{
Vladimir E. Martínez-Bello ${ }^{\mathrm{a}, \mathrm{b}}$, Yolanda Cabrera García-Ochoa ${ }^{\mathrm{a}, \mathrm{c}}$, José Díaz- Barahona ${ }^{\mathrm{a}, \mathrm{b}}$ and \\ María del Mar Bernabé-Villodre ${ }^{a, b}$ \\ ${ }^{a}$ Body, Movement, Music and Curricular Practices - COS Research Group, University of Valencia, Valencia, Spain; \\ ${ }^{\mathrm{b}}$ Department of Musical, Visual, and Corporal Expression Teaching, Faculty of Teaching, University of Valencia, \\ Valencia, Spain; 'Department of Language Theory and Communication Sciences, Faculty of Philology, Translation \\ and Communication, University of Valencia, Valencia, Spain
}

\begin{abstract}
To our knowledge, no studies have used Bourdieu's theoretical contributions to frame investigations on how early childhood education (ECE) teaching materials construct body differences in a way that justifies gender inequality. For Bourdieu, the power to classify and grant properties and signs to subjects, does not reside only in the power to impose, but also in the degree to which the vision is anchored within reality. Therefore, the aims of this study is to assess the representation of the body in the curricular materials of ECE classrooms in 10 public centers, by means of quantitative content analysis and to provide, using Pierre Bourdieu's theoretical framework on the construction of the body, a qualitative critical analysis of the gendered discourses on the construction of the body that the visual depictions of the bodies transmit in ECE classrooms based on the perceptions of a group of ECE educators and students. Our results show that these images do not represent children as individuals, but rather as subjects with socially constructed labels that favor stereotypical roles. Both teachers and students relate their own training with the curricular practices they perform in their classrooms suggesting that visual representations are both abstractly embedded into institutional practices as well as practically integrated into educational work through curricular materials. In conclusion, they recognize that the fight against taxonomies and labels with which the body is constructed is a process linked to the identity and autonomy of the agents who are participating in education.
\end{abstract}

\section{ARTICLE HISTORY}

Received 8 July 2019

Accepted 5 November 2019

\section{KEYWORDS}

Body; gender; curricular materials; Bourdieu; early childhood education

\section{Introduction}

Bourdieu (1998) described how institutions like the family and the school inscribe a set of messages on male and female bodies, perpetuating situations of discrimination. The context in which the body operates plays a fundamental role in the construction of these messages, and by extension, in its possibilities to act. Bourdieu (1998) stated that

one's relationship to their body cannot be reduced to its image, that is, to the subjective representation ... such a model disregards that the entire social structure is present at the core of the interaction, underlying the form of the schema of perception and appreciation, which is inscribed in the body of the interactive agents (p. 70).

CONTACT Vladimir E. Martínez-Bello vladimir.martinez@uv.es B Body, Movement, Music and Curricular Practices - COS Research Group, Department of Musical, Visual, and Corporal Expression Teaching, Faculty of Teaching, University of Valencia, Av. Tarongers 4, València, Valencia, Spain 
In this way, the social world is presented objectively as a symbolic system organized according to the logic of difference, or the differential gap or separation-a construction which is never neutral (Bourdieu, 1998).

Within this framework that clearly rationalizes difference, the gendered construction of the body explains how society shapes physical bodies and vice versa. In fact, Connell (2005) argues that gender is a social practice that constantly refers to bodies and what bodies do, but it is not reduced to the body. Regarding the construction of femininity, Butler (1990) signaled the need to search for alternative models that did not distort women's integrity and undermine their full participation in society.

Furthermore, the discourses that Fairclough (2003) describes are 'ways of representing aspects of the world', which in turn generate other discourses 'associated with the different relations people have to the world, which in turn depends on their position in the world, their social and personal identities, and the social relationship in which they stand to other people.' For this author, these forms of representation depend on the subject's position in the world, which is materialized through three broad avenues: personal identity, social identity, and the way that social relations with others are generated. Bourdieu (1987) calls this 'habitus', or 'the sense of place one occupies and a sense of the place occupied by others' (p. 156).

Given the polarized principles of male and female identity, codified in behaviors and the maintenance and management of the body (Bourdieu, 1998), 'the social representation of the body, which each agent must consider from a very young age, is obtained by applying a social taxonomy whose principle coincides with that of the bodies to which it is applied' (Bourdieu, 1998, p. 71). In early childhood education (ECE), Blaise (2005) warns that ignoring gender within curricular practices is akin to failing to recognize how children's identities are constructed and reconstructed, and how these play a role in promoting social justice. In this way, as Mac Naughton (2005) argues, ECE must expose the ideologies-uncovering the invisible-as a first step toward challenging the power relationships that these ideologies conceal and support.

As Kelly-Ware (2016) points out in the context of ECE, heteronormativity is a dominant discourse that has a powerful influence on people's lives. For the author, girls and boys are capable of engaging in various gender performances related to the construction of their identities. In other words, 'children do gender and their performances can vary depending on their ongoing working theories as well as contextual factor such as time, space/place and associates' (Kelly-Ware, 2016, p. 153).

In this line, subjects' expectations when interpreting social reality make what is culturally constructed seem natural. Grundy (1998) made a similar point, saying that one aspect of ideology is how the set of dominant ideas, which in some way deforms reality, naturalizes ideas that are culturally constructed. In terms of constructing discourse, Fairclough (2003) called this 'ideological common sense'. In any case, the situation becomes problematic when this normalization serves to maintain unequal power dynamics, becoming oppressive or facilitative. For Butler (1990), 'discourse become oppressive when it requires that the speaking subject, in order to speak, participate in the very terms of that oppression - that is, taking for granted the speaking subject's own impossibility or ineligibility' (p. 116).

To our knowledge, few studies have used Bourdieu's theoretical contributions (Bourdieu, 1979; Bourdieu, 1989; Bourdieu, 1998; Bourdieu \& Wacquant, 1992) to frame investigations on how ECE teaching materials construct body differences in a way that justifies gender inequality. However, some authors have used other models and theoretical approaches to show that images in different teaching materials, including story books and coloring books, can reproduce, transmit and reinforce gender stereotypes that generate masculine and feminine standards (Varea \& Pang, 2018). Since the well-known publications of Weitzman, Eifler, Hokada, and Ross (1972) and Rachlin and Vogt (1974) in the 1970s, as well as the Spanish studies by Garreta and Careaga (1987), Blanco García (2000), García-Ochoa and Martínez-Bello (2014), it has been clear that gender stereotypes in teaching materials foster discrimination among children from the earliest stages of their education.

Within this framework, a recurring practice for studying messages in ECE curricular materials has been quantitative content analysis of how the body is constructed through culture, using previously 
established, dichotomized categories like 'girl-boy,, 'child-adult,' or 'abled-disabled'. In Spain, MartínezBello and Martínez-Bello (2017) showed that the messages impressed on the walls of ECE classrooms can 'teach' gender equality to young children. However, this quantitative analysis fails to consider that children's bodies assume certain taxonomies and labels. These could be critically examined through qualitative analysis of how the surrounding discourses regulate the body, for example through clothing, body language, and power relations. These manifestations are explicit and latent expressions of the discrimination and exclusion of female bodies. In fact, the discourse analysis of the visual representations also implies an interpretation and analysis of what is not represented or said (Rose, 2016): absences and silences position, legitimize and assign hierarchies to bodies' possibilities by virtue of the lack of models where diversity is the norm and not the exception. In fact, from an emancipatory perspective, the teaching function must challenge the reproduction of discriminatory situations through artefacts, instruments and teaching materials. For example, regarding training in aspects of teachers' ideological criticism, Brown (1998) argued that this 'implies making decisions about what to teach, how to teach it, when to teach ... It is essential that we know the "hidden curriculum." For example, what criteria do we use when selecting books, games, and other learning resources?' (p. 50).

Thus, this study uses a gender perspective to investigate what discourses are constructed and transmitted in the ECE classroom, in terms of the visual representations of masculine and feminine bodies and their possibilities for action. Our primary objective is to assess the representation of the body in the curricular materials of ECE classrooms in 10 public centers in a continental European country, by means of quantitative content analysis. The secondary objective is to provide a qualitative description of the gendered discourses on the construction of the body that the visual depictions of the bodies transmit in ECE classrooms, based on the perceptions of a group of ECE educators and graduate students. We will pursue these aims using Pierre Bourdieu's theoretical framework on the construction of the body (Bourdieu, 1979; Bourdieu, 1989; Bourdieu, 1998; Bourdieu \& Wacquant, 1992). Based on Bourdieu's vision it is not so much a question of how teachers construct the body but in how they perceive the social representation of the body from the visual representations of the masculine and feminine bodies. In this research, the aim will be to use Bourdieu's theoretical heritage as a tool for recognizing the construction of difference between bodies. We consider that these two methodological approaches (content analysis and critical qualitative analysis) are complementary to deciphering how social taxonomies affect the way children's bodies are constructed in the ECE classroom.

\section{Methods}

\section{Selection of study centers}

A descriptive, observational, critical, mixed-methods study was designed. The project took place during the 2016-2017 academic year, with the support of different centers in the province of Valencia (Spain). Ten public centers in the metropolitan area of Valencia were assessed following authorization from the schools' administrators. Classrooms were selected using convenience sampling, with ECE teachers invited to participate. In the centers with a single class per grade, that classroom was chosen.

\section{Selection of classrooms}

The study involved 10 ECE centers and 20 classrooms. Once the centers were selected, classrooms were selected using convenience sampling, with ECE teachers invited to participate. The research team explained the study objectives and activities to the teachers in charge of the classrooms. Of these (depending on the extent of each ECE) teachers were invited to participate in the study in two ways: first, by allowing the photographic recording of all the visual representations of the body that were present in their classrooms, and, second, by participating in a semi-structured interview. Once they agreed to collaborate, we opted to select two classrooms per ECE level (3-year-olds, 4-year-olds, and 5-year-olds). In the centers with a single class per grade, that classroom was chosen. In total, the study assessed 20 classrooms. 


\section{Sampling method and data collection}

Once the classrooms were selected, we selected the registry units, that is, the media and devices containing visual representations of bodies (humans, anthropomorphized animals, fantasy figures, etc.). A catalogue was generated to show how the bodies in the ECE classrooms were located and what type of activities each was doing. The photographs of the visual representations were collected when the children were not in the classroom. The 'location' of the bodies refers to an ad-hoc classification of the media where these visual representations appeared: commercial material, material developed by teachers, children's book or textbook cover, doll, children's drawing, and photograph. Each of these representations was photographically recorded. From each classroom, the registry units were selected using simple random sampling methods: all of the units were numbered and then chosen using a random numbers table. The sampling error was $+7 \%$, with a confidence level of $90 \%$. The final sample consisted of 770 photographs of visual representations of the body. Each registry unit was subjected for the subsequent content analysis, following the protocol described above.

\section{Analytical techniques}

All 770 photographs were subjected to a quantitative content analysis. Content analysis is a quantitative technique that favors study of the transmission of meaning by registry units, through an interpretation based on the construction of a system codifying categories and indicators. Before undertaking the definitive analysis of the images, we performed a pilot study with $20 \%$ of the total sample in order to assess interobserver agreement. The quantitative analysis was done independently by a pair of observers who had received training on the categories and indicators but who were unaware of the study objectives. An interobserver reliability test was conducted independently in both observers, showing a concordance of $\mathrm{k} 0.6-0.8$ for the categories used. Following this test, we proceeded to the definitive analysis of the images and the quantification of the data obtained. A system of categories and indicators was used, with special attention to the representation of characters in the images, in consonance with the methodology followed by Martínez-Bello and MartínezBello (2017). The categories were: gender, age, physical activity (PA), clothing, color of clothing, group composition, type of character, body position, and type of curricular material.

\section{Interviews of teachers and students}

Of the twenty classrooms from which the visual representations of the body were taken, only twelve ECE teachers could participate (the rest declined for personal reasons or scheduling conflicts). All the teachers had the degree of ECE Teacher-a prerequisite for teaching 3- to 6-year-olds in a public school-and were responsible for each classroom. In addition, 12 last-year ECE students (from a total of four years) in the faculty participated in the study. The students had no previous contact with the classroom or with the ECE teachers in those classrooms.

Twelve teachers and twelve students were subjected to an 8-12 min interview. The interviews with the teachers were accompanied by a projection of 16 photographs of curricular materials used in the 20 included classrooms. Therefore, we extracted 8 photographs that were representative of the most important results found in the quantitative content analysis: 1. Female bodies were represented more performing sedentary behaviors than male bodies. 2. Female bodies were represented more with soft colors, while male bodies were represented more with hard colors. 3. Male bodies were related to stereotyped male body postures, while female bodies were related to stereotyped female postures. The purpose of the interview was for the teachers to have the opportunity to discuss the meanings of the constructed body in the overall sample taken for content analysis. The remaining 8 photographs that were used in the interview were randomly selected from the set of photographs that each teacher had in their classroom in order to provide them an opportunity to analyze the 
meanings of the bodies projected in the curricular materials they routinely use. For the interviews with the ECE students, the same photographs used with ECE teachers were taken Figure 1.

The interview items were: 1. Describe what you observe in the images. 2. What is the teacher's purpose for showing this image? 3. What meanings do the images transmit? 4. What does gender equality mean to you? and 5 . Tell us about your training related to gender equality. Taylor and Bogdan (1987) considered that documents like diaries, drawings, letters, and agendas can be used to guide interviews without imposing a structure on the respondents, as the materials can evoke memories and old feelings.

\section{Procedure for the qualitative analysis of ECE teachers and ECE students' perceptions}

Data from the audiotapes were transcribed in a Word document immediately following the interviews. A critical qualitative analysis of the transcript was performed by selecting units of analysis,
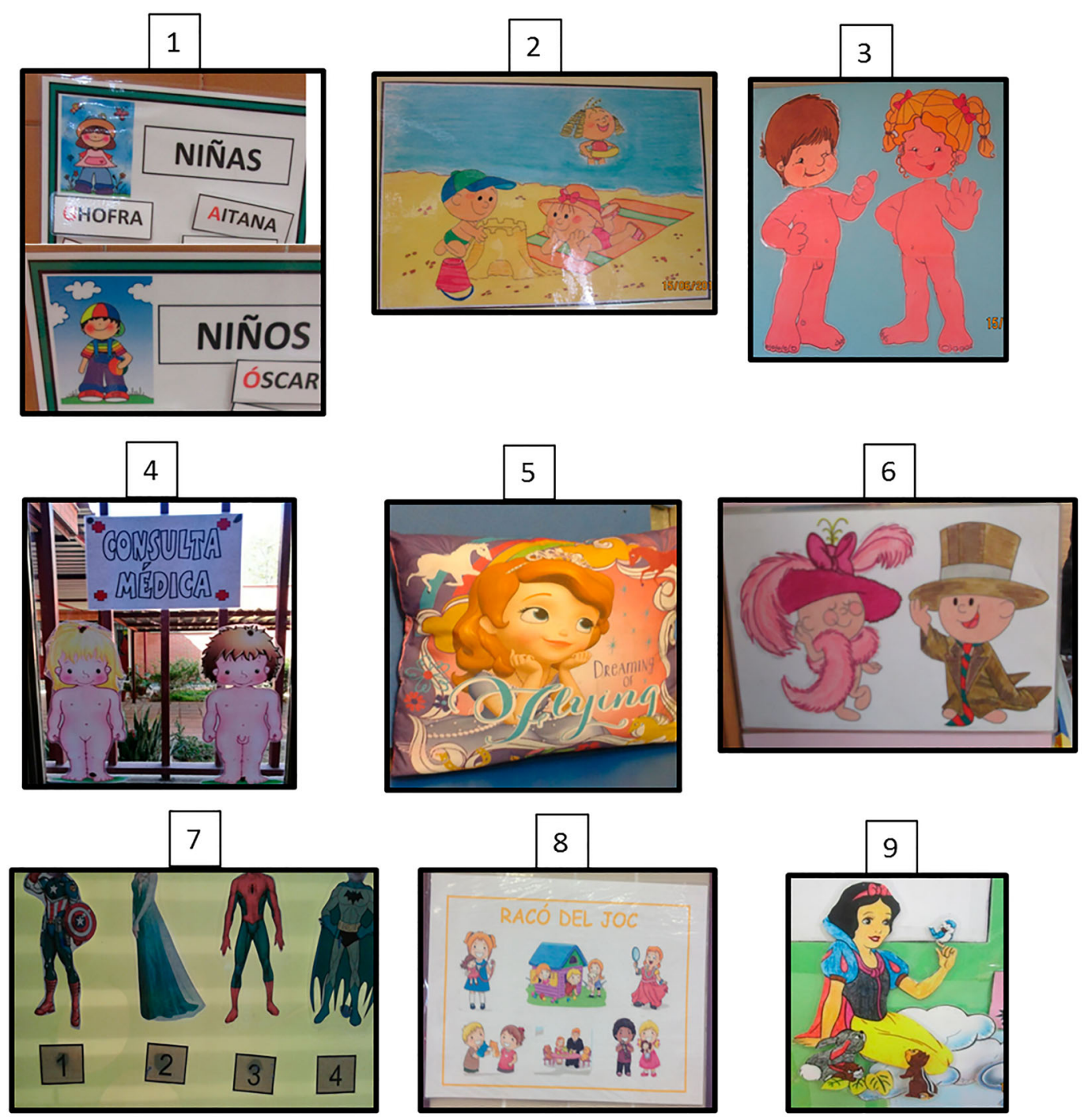

Figure 1. Some examples of photographs of bodies used in the interviews with ECE teachers and students. 
coding them, and then classifying them. Each participant was classified with their corresponding interview. Fairclough (2001) stated that the producer of a text constructs that text as an interpretation of the world, from the perspective of the world concentrating the attention. Thus, whoever interprets the text (or in our case, the visual representation) bases their understanding of it on the expectations of the text's creator. With this in mind, we wanted to obtain an interpretation of an interpretation of many texts, or in other words their discourses, as they were presented in the ECE classrooms.

The categories were constructed a posteriori, based on the detection of common elements in each interview. We followed the three stages Fairclough (2001) proposed for discourse analysis: description, interpretation, and explanation. The descriptive phase used units of meaning, which were selected based on an initial descriptive reading of the way the subject was described. In the interpretative phase, we identified the discourses within which the body is embedded (clothing, make-up, mannerisms). Finally, using the concept of habitus (Bourdieu, 1987) whenever possible, we identified the discourses that the body transmits, that is, the way in which the subjects construct the social world and their expectations within it. To obtain a measure of reliability for the coding, two investigators independently analyzed the interview data. Once each of the categories was identified, these were corroborated by the other investigator. The data from the interviews were classified into 21 initial categories, and these were grouped following a joint review by both investigators, which produced a definitive list of 7 categories (Table 4). Furthermore, pseudonyms were used in order to protect participants' privacy.

\section{Statistical analysis}

A descriptive analysis was used to represent the main categories. To find associations between them in the sampling units and registry units, the chi-squared test was applied. Contingency tables were constructed, using gender as the reference to assess associations with other categories. Where differences did not reach statistical significance $(p<0.05)$, we described these differences narratively. All statistical analyses were undertaken using SPSS (version 22) software.

\section{Results}

\section{Quantitative results}

With regard to the study indicators according to gender, Table 1 shows that of the 770 bodies analyzed the level of PA shown in the images is Light/moderate PA (40\%) for males, compared to Sedentary $(60 \%)$ and to a lesser extent the Light/moderate PA (32\%) for females, compared to Sedentary $(68 \%)$; these differences were statistically significant ( $p=0.03$; Cramer's $V=0.08$ ). In terms of interaction or group composition, for females we observed the following distributions: Group girls and boys (38\%), Solitary (34\%), and Groups of girls and Group with adult (11\% each). For males, the most frequent group composition was Solitary (38\%), and Group girls and boys (36\%). The chisquared test showed a statistically significant association between these categories $(p=0.001$; Cramer's $V=0.2$ ). For the category of clothing, we did not observe significant differences between gender categories. In terms of the association between gender category and color, there was a statistically significant association. Males generally appeared in Neutral colors (53\%) or Blue/hard colors (38\%), with just $1 \%$ appearing in pink/soft colors. About half $(51 \%)$ the female characters were dressed in neutral colors, and $41 \%$ in pink/soft colors. The chi-squared test showed that these differences were statistically significant ( $p=0.001$; Cramer's $V=0.62)$.

With regard to the body posture, male characters mostly appeared in Neutral posture (75\%), Stereotypical male postures (24\%), and exceptionally in Stereotypical female postures (1\%). Females mostly appeared in Neutral postures (81\%), followed by Stereotypical female postures (18\%) and Stereotypical male postures (1\%). The chi-squared test showed that these differences were statistically significant ( $p$ $=0.001$; Cramér's $V=0.45$ ). 
Table 1. Frequencies and percentages (\%) of characteristics based on gender.

\begin{tabular}{|c|c|c|c|c|}
\hline & & Males & Females & $x^{2}$ \\
\hline \multirow[t]{3}{*}{ Activity level } & & & & $4.902 ; \mathrm{df}=1 ; p=0.03^{* *}$ Cramér's $V=0.08$ \\
\hline & Sedentary & $252(60)$ & 237 (68) & \\
\hline & Light/moderate PA & $168(40)$ & $113(32)$ & \\
\hline \multirow[t]{4}{*}{ Age } & & & & $3.459 ; \mathrm{df}=2 ; p=0.177$ Cramér's $V=0.07$ \\
\hline & Child & $303(72)$ & $260(74)$ & \\
\hline & Adult & $107(26)$ & $76(22)$ & \\
\hline & Older adult & $9(2)$ & $14(4)$ & \\
\hline \multirow[t]{6}{*}{ Group composition } & & & & 23.735; $\mathrm{df}=4 ; p=0.001^{* *}$ Cramér's $V=0.2$ \\
\hline & Solitary & $161(38)$ & $118(34)$ & \\
\hline & Group girls & $17(4)$ & $40(11)$ & \\
\hline & Group boys & $50(12)$ & $20(6)$ & \\
\hline & Group girls and boys & $149(36)$ & $132(38)$ & \\
\hline & Group with adult & $43(10)$ & $40(11)$ & \\
\hline \multirow[t]{5}{*}{ Type of character } & & & & $21.408 ; \mathrm{df}=3 ; p=0.001^{* *}$ Cramér's $V=0.17$ \\
\hline & Human & $368(88)$ & $299(86)$ & \\
\hline & Animal & $33(8)$ & $22(6)$ & \\
\hline & Fantastic & $10(2)$ & $29(8)$ & \\
\hline & Superheroes & $9(2)$ & - & \\
\hline \multirow[t]{3}{*}{ Clothing } & & & & $0.485 ; \mathrm{df}=1 ; p=0.512$ Cramér's $V=0.025$ \\
\hline & Naked/semi-naked & $37(9)$ & $26(7)$ & \\
\hline & Regular clothes & $383(91)$ & $324(93)$ & \\
\hline \multirow[t]{5}{*}{ Color stereotypes } & & & & $298.019 ; \mathrm{df}=3 ; p=0.001^{* *}$ Cramér's $V=0.62$ \\
\hline & Blue (Hard colors) & $159(38)$ & - & \\
\hline & Pink (Soft Colors) & $2(1)$ & $143(41)$ & \\
\hline & Neutral & $222(53)$ & $178(51)$ & \\
\hline & Non clothes & $37(9)$ & $29(8)$ & \\
\hline \multirow[t]{4}{*}{ Body posture } & & & & $155.607 ; \mathrm{df}=2 ; p=0.001^{* *}$ Cramér's $V=0.45$ \\
\hline & Male stereotype & $104(24)$ & $1(1)$ & \\
\hline & Female stereotype & $2(1)$ & $64(18)$ & \\
\hline & Neutral & $314(75)$ & $285(81)$ & \\
\hline \multirow{7}{*}{$\begin{array}{l}\text { Kind of curricular } \\
\text { material }\end{array}$} & & & & $13.239 ; \mathrm{df}=5 ; p=0.06$ Cramér's $V=0.13$ \\
\hline & Commercial material & $180(42)$ & $174(50)$ & \\
\hline & Material developed by teachers & $125(30)$ & $80(22)$ & \\
\hline & $\begin{array}{l}\text { Children's book or textbook } \\
\text { cover }\end{array}$ & $54(13)$ & $31(9)$ & \\
\hline & Doll & $29(7)$ & $28(8)$ & \\
\hline & Children's drawing & $17(4)$ & $27(8)$ & \\
\hline & Photograph & $15(4)$ & $10(3)$ & \\
\hline
\end{tabular}

$N=770$

With regard to the characteristics based on body posture and in relation to the level of PA, color stereotypes and age in each gender (Table 2), $42 \%$ of the males and $68 \%$ of the females appear in a Sedentary, while $58 \%$ and $32 \%$, respectively, are taking part in Light/moderate PA. The chi-squared statistic shows an association between the two categories ( $p=0.02$; Cramér's $V=0.25)$. Regarding color stereotypes, we see that males were associated with the color blue (or similar hard colors) in $75 \%$ of the images where they appeared, compared to Neutral colors $14 \%$ of the time, Non clothes in $10 \%$, and only anecdotally (1\%) in soft colors like pink. In contrast, females were represented in Pink in $82 \%$ of the images, while they appeared in Neutral colors in only $14 \%$ and without clothing in $5 \%$. These data showed statistically significant differences according to the chi-squared statistic ( $p=0.001$, Cramer's $V=0.88)$.

Finally, in terms of other variables related to personal appearance and dress, Table 3 shows the most predominant features in males to be: Short hair (52\%), Long pants (25\%), Hat (6\%) or Cap (5\%). Long hair, Shorts, and Ties appear in just a handful of images $(\leq 4 \%)$. The most defining features in the images of females were Long hair (48\%), followed by clothing and accessories like Dresses (16\%), Hair accessories (14\%), and Skirts (12\%). Just $1 \%$ of the females were represented as wearing shorts or having short hair. 
Table 2. Frequencies and percents (\%) of characteristics based on body posture and activity level, color stereotypes and age.

\begin{tabular}{|c|c|c|c|c|}
\hline & & $\begin{array}{c}\text { Male } \\
\text { stereotypical } \\
\text { body posture }\end{array}$ & $\begin{array}{c}\text { Female } \\
\text { stereotypical } \\
\text { body posture }\end{array}$ & $x^{2}$ \\
\hline \multirow[t]{3}{*}{ Activity level } & & & & $10.836 ; \mathrm{df}=1 ; p=0.02^{* *}$ Cramér's $V=0.25$ \\
\hline & Sedentary & $44(42)$ & $45(68)$ & \\
\hline & $\begin{array}{l}\text { Light/moderate } \\
\text { PA }\end{array}$ & $60(58)$ & $21(32)$ & \\
\hline \multirow[t]{5}{*}{$\begin{array}{l}\text { Color } \\
\text { stereotypes }\end{array}$} & & & & $\begin{array}{l}\text { 132.467; } \mathrm{df}=3 ; p=0.001^{* *} \text { Cramér's } V= \\
0.88\end{array}$ \\
\hline & Blue (Hard colors) & $78(75)$ & - & \\
\hline & Pink (Soft Colors) & $1(1)$ & $54(82)$ & \\
\hline & Neutral & $15(14)$ & $9(14)$ & \\
\hline & Non clothes & $10(10)$ & $3(5)$ & \\
\hline \multirow[t]{4}{*}{ Age } & & & & $2.209 ; \mathrm{df}=2 ; p=0.33$ Cramér's $V=0.1$ \\
\hline & Child & $65(62)$ & $46(70)$ & \\
\hline & Adult & $33(32)$ & $19(29)$ & \\
\hline & Older adult & $6(6)$ & $1(1)$ & \\
\hline
\end{tabular}

$N=170$.

\section{Discussion}

\section{Content analysis and critical qualitative analysis of the discourses}

In this study, we have categorized the messages inscribed on the visual representations based on preestablished criteria. The images from 20 ECE classrooms reflect an underrepresentation of females and different patterns of PA according to gender. We also detected a positive association between gender and the categories of 'Stereotypical colors', 'Levels of PA,' and 'Body posture', suggesting that children's bodies are constructed using different social parameters related with color, posture, and possibilities for movement.

Additionally, as a result of the interviews undertaken in ECE teacher and ECE students about the messages transmitted by visual representations of bodies, and after consolidating the themes covered based on consensus between the two researchers who independently undertook the qualitative analysis, we extracted content on seven definitive thematic categories, shown in Table 4.

Both the quantitative and qualitative results were jointly analyzed to describe a context that facilitates reflection on the construction of the body in the ECE classrooms participating in the study.

\section{Sources of visual representations of bodies in ECE classrooms}

The quantitative analysis of the centers visited showed that about $25 \%$ to $35 \%$ of the images of bodies corresponded to curricular materials that were reconstructed by the teachers (Table 1). One of the most frequently used sources for images was the internet; for example, teachers will use a search engine to look for images of 'girls playing', and they choose from a variety of photographs and images according to their teaching needs:

Table 3. Character indicators according to gender.

\begin{tabular}{lrlr}
\hline Male characters & $\%$ & \multicolumn{1}{c}{ Female characters } & $\%$ \\
\hline Short hair & 52 & Long hair & 48 \\
Long pants & 25 & Dress & 16 \\
Hat & 6 & Hair accessories (bow, flower) & 14 \\
Cap & 5 & Skirt & 12 \\
Short pants & 4 & Pigtail & 4 \\
Moustache & 2 & Necklaces & 2 \\
Tie & 2 & Bag & 2 \\
Long hair & 1 & Short hair & 1 \\
& & Short pants & 1 \\
\hline
\end{tabular}

$N=170$. 
Table 4. Initial and final categories from qualitative analysis of interviews in teachers and students

\begin{tabular}{|c|c|}
\hline \multicolumn{2}{|c|}{ Categories } \\
\hline Initially identified categories & Final categories \\
\hline $\begin{array}{l}\text { Use of textbooks or other curricular materials } \\
\text { Internet, online journals/magazines } \\
\text { Commercial materials or materials developed by teachers }\end{array}$ & Sources of visual representations of bodies in ECE classrooms \\
\hline $\begin{array}{l}\text { Detection of neutral messages in the images } \\
\text { Detection of social attributes related with the male and } \\
\text { female body in the images } \\
\text { Detection of how to act and behave based on images of the } \\
\text { body }\end{array}$ & $\begin{array}{l}\text { Recognition of the body-gender taxonomy in visual } \\
\text { representations of the body }\end{array}$ \\
\hline $\begin{array}{l}\text { Curricular justification for using the images } \\
\text { Neutrality of the images } \\
\text { Naturalization of the gender discourse in school and society }\end{array}$ & $\begin{array}{l}\text { Difficulty in detecting the body-gender taxonomies in the } \\
\text { curricular materials }\end{array}$ \\
\hline $\begin{array}{l}\text { The family as a transmitter of distorted messages } \\
\text { Media, children's programing and films that perpetuate the } \\
\text { distortion } \\
\text { The role of the society at large in perpetuating stereotypes }\end{array}$ & $\begin{array}{l}\text { Reasons explaining the presence of body-gender taxonomies in } \\
\text { visual representations }\end{array}$ \\
\hline $\begin{array}{l}\text { Active attitude about the construction of original curricular } \\
\text { material } \\
\text { Effect of gender discourses on faculty's life } \\
\text { Need for emancipation among faculty }\end{array}$ & $\begin{array}{l}\text { Sensitivity among faculty and student teachers regarding } \\
\text { gender issues }\end{array}$ \\
\hline $\begin{array}{l}\text { Other possible ways of working in the classroom } \\
\text { Identification of ethical responsibilities } \\
\text { Emancipation is necessary after sensitization }\end{array}$ & Recognition of alternatives for combatting body stereotypes \\
\hline $\begin{array}{l}\text { Gradual generation of social change } \\
\text { Need for more training on the construction of the body } \\
\text { through gender } \\
\text { University and continuous training }\end{array}$ & The role of training on gender equality \\
\hline
\end{tabular}

... We often use images from the internet, images from magazines, images from editorials ... - Teacher A.

The teachers selected images in line with their way of perceiving the world and the possibilities of movement and based on other elements that signified 'girl' or 'boy' to them. Within this framework, Fairclough (2001) noted, 'Not all photographs are equal: any photograph gives one image of a scene or a person from among the many possible images ...' (p. 41). Thus, the teacher becomes a producer of texts infused with meaning.

\section{Recognition of the body-gender taxonomy in visual representations of the body}

One of the principle findings of the study consists of the common positioning of both ECE teachers and ECE students with regard to detecting messages inscribed on the bodies represented visually in the images. The recognition of the discourses surrounding the body is regulated by the identification of certain attributes and attitudes that accompany it, wherein the differences between the biological and socially constructed body are related. One of the teachers explained this as follows (images \# 1, 6 and 8):

... Even if I want to interest a boy in ... that pink doll, even being as little as they are, there are still some that reject it because it's pink, 'that's a girl' ... the one that's the boy and the one that's a girl, I have them reflect on that. - Teacher $\mathrm{H}$.

Within this context, for Barthes (1977), 'the reading of the photograph is thus always historical; it depends on the reader's 'knowledge' just as though it were a matter of a real language, intelligible only if one has learned the signs' (p. 28). In fact, the teachers recognized different discourses embedded in girls' bodies compared to boys' bodies, negotiating the meanings transmitted by the images. Bourdieu (1998) argued that 'the existing taxonomies tend to face off, forming a hierarchy, with the most frequent characteristics divided into those that are dominant and those that are dominated (thin/fat, big/small ...)' (p. 71). Regarding this identification of the hierarchy of messages that bodies transmit, one student and a teacher said: 
It's like the girl is trying to please the boy, and she's in pink because she's like a quote-unquote 'girli, so she has to be in pink ... and the boy ... a brownish green ... like he's trying to pick up the girl, so to speak. - Student $C$.

To me it stands out that the girl ... is lying down when she could be doing other things on the beach ...I think that girl would have more fun if she was doing something, moving; I don't know if she should be helping the other person make the sandcastle or going to swim-one of the two things to not be just lying there watching - Teacher D.

For Bourdieu (1996),

judgments meant to apply to a whole person clearly take into account not only strict physical appearance, which is always socially marked, but also clothing, accessories, make-up, and especially manners and behavior, which are perceived according to socially constituted taxonomies ... (pag. 35).

In this line, the posture of the girl's body is spontaneously perceived as an indication of the sweet and delicate 'form' of being a girl (Table 3), which is therefore correct. On the contrary, any girl that defies that normalized attitude is perceived as different. Butler (1990) indicates that

the mark of gender appears to 'qualify' bodies as human bodies ... those bodily figures who do not fit into either gender fall outside the human, indeed constitute the domain of the dehumanized and the object against which the human itself is constituted (p. 151).

One teacher says:

Seeing that the girls are this way, and if you're a girl you have to behave this way, and if you're a boy you have to behave that way. If not, you're different, you're a weirdo

-Teacher $\tilde{N}$.

In addition, we detected a discourse based on nature (the visualization of genitals), in which the ECE teachers perceived a naturalization of meanings that were culturally established (see images \# 3 and 4). The visualization of genitals was one of the 'distinctive features' that teachers detect when interpreting the gender of the bodies represented in the images. Here, we refer to the naturalization of the discourse, that is to say, that some teachers report that they look to the genitals in order to decide whether the image represents a boy or a girl. However, as can be observed, the image automatically and totally turns towards culture, with the female body appropriating the most characteristic elements of femininity (in terms of heteronomartivity). Thus, what in the beginning would be a biological body plus culture, is now a simple amalgam. We say simple because it is to be expected as a product of common sense. In the words of Fairclough (2001), 'ideological common sense in the service of sustaining unequal relations of power' (p. 70).

In this way, the different signs maintain their intrinsic and unshakeable properties. For example, a hairbow cannot be black or dark in color: its property - the element that shapes it as an entity in the eyes of the body that wears it, and therefore in the eyes that reproduce the meanings of the visual representation-cannot be anything other than a light or soft color that matches the clothing or the rest of the colors associated with the body. Therefore, the color, the shapes and the gestures appear as a logical and expected result. One teacher comments on this 'common sense':

I for one do believe, based on my own life ... that a woman, well, wants to feel protected ..., the Olympics don't mix men and women ... because they wouldn't be playing in the same conditions, or at least that's what is believed. So, I think that women and men are different as far as emotions and strength go, physically. - Teacher I.

Moreover, ECE teachers and ECE students identify in the visual representations of female bodies, especially, the idea of an infantilized and angelical body (see image \# 4). For example, student $\tilde{N}$ says:

... the princess is more fragile, with her hands together and a long dress completely representing the values that society stipulates for a woman, and that really it's the man that has to save the princess. The superhero is always the one that saves the princess ... - - Student $\tilde{\mathrm{N}}$.

In fact, as Bourdieu (1998) proposes, the female becomes a being who is perceived. He writes, 'male domination, which turns women into symbolic objects, whose being is a perceived being, has the 
effect of putting them in a permanent state of body insecurity or, in other words, of symbolic dependence' (p. 73). In this line, the female body faces a double normalization. On top of its presentation as angelical or innocent, stereotypically feminized postures are also imposed (Table 3), for example flirtatiousness or sexualization in childhood. In fact, 'this heteronomy is the beginning of dispositions like the desire to draw attention and please, sometimes called coquetry, or the propensity to expect a lot from love' (Bourdieu, 1998, p. 73). One of the students had the following to say on the topic, based on the image below of the girl in pink and the boy in the top hat (see image \# 6):

They look like a boy and a girl ... the boy is dressed in a hat and a suit and a tie, and the girl, well she's got a hat, a hairbow ... It's like the girl is trying to please the boy, and she's in pink because she's like a quote-unquote 'girl,' so she has to be in pink ... and the boy ... a brownish green ... like he's trying to pick up the girl, so to speak. Student $\mathrm{C}$.

Finally, it is notable that the graduate students were able to identify the relationship between the attributes linked to gender as well as with the representations of the anthropomorphized animals. For example:

Some penguins appear, one with a red hat and swimming in front, and another penguin is pink and has a bow, with pink cheeks that make you think ... it's a boy with a male gender, and he's up front swimming, and then the female penguin, the woman, is following him, because she's pink and is wearing a bow. - Student $\tilde{N}$.

\section{Difficulty in detecting the body-gender taxonomies in the curricular material}

Following Barthes' (1977) thoughts on what a photograph transmits to the viewer, we proceeded to ask participants what the visual representations transmitted to them, including the images in their own classrooms. In this same line, Fairclough (2001) writes, 'the producer of the text constructs the text as an interpretation of the world, or of the facets of the world which are then in focus; formal features of the text are traces of that interpretation' (p. 67). In this framework, three subcategories were detected in relation to the presence of distorted body meanings linked to gender in ECE classrooms: (a) the question of conformism; (b) the absence of critical capacity in the detection of stereotypes, together with an extended normalization of the vision of gender, and (c) priority of the use of the image in accordance with the teaching objectives.

With respect to the category, 'Question of conformism' (a), the ECE teacher is aware that the lack of time or certain administrative factors preclude a prior analysis of the distortions of the images. One teacher explains:

Often due to a question ... of time ... you just search for 'images of children' ... for the boys, girls, and sometimes we don't even notice the clothing or the attitude ... you don't realize it until someone points it out. - Teacher K.

In the following commentary, the 'Normalization of the construction of gender' (b) is evident (see image \# 7):

... the thing is that they really strongly identify—why, these [girls] were all into Frozen ... my girls weren't girls with strong personalities ... to allow them to have a voice, I had to constantly stop the boys, because they would eat [the girls] alive - Teacher $\mathrm{H}$.

In any case, the meanings that the images transmit have a logic based on difference which would be, from a superficial perspective, natural, created by the simple flow of history. However, the opposite is the case; it is knowingly constructed by the same actors by means of their curricular practices. In this way, the logic of difference is organized, according to Bourdieu (1998), as a form of 'common sense' through a symbolic system: 'the dominated apply a set of constructed categories to the relationships of domination, from the perspective of the dominators, making them seem natural' (p. 41). This dynamic is apparent in the following image (see image \# 8):

In the same way, on inquiring about the teachers' perceptions of the presence of sexist stereotypes and how to address them, we observed a combination of the subcategories 'Conformism' and 'Absence of critical capacity'; these were merged into a common category: 'Resistance.' 
Nowadays it's all a little exaggerated ... they make us put everything in the feminine and masculine. - Teacher I.

Generally speaking, one of the factors that has favored the distorted construction of girls' and boys' possibilities and attributes is linked to children's incompetence in constructing and reconstructing their gender (Blaise, 2005):

The girls aren't really aware because a lot of information has been put into their head. - Teacher $\mathrm{N}$.

At the same time, teachers recognize the use of images for didactic purposes (c), such as: seasons, the human body, numbers, and behavioral rules-examples of images that are, therefore, pleasing and motivating to the children:

The characteristics of each season and each garment, more than the children themselves [have an impact on???]. But obviously, depending on the season, the kids wear some clothes or others ... then of course, taking it out of context, then I see it in the classroom and it turns out it's not because of the season. - Student A.

Therefore, these systems for producing practices coexist, expending efforts both to rationalize the unbreakable common sense of things and to fight against the common sense of bodies and of creators' and observers' expectations of the images. Likewise, the discourses are under debate between a system of logic based on difference, created by the simple flow of history, and another logic of intentional construction, put forward intelligently by the same agents who introduce the discourses into the social world and reinforce them constantly through their own curricular practices. As Bourdieu (1998) put it, 'women can only become what they are according to mythical reason ... they are condemned at all times to give the diminished identity that has been socially attributed to them the appearance of a natural foundation' (p. 36).

\section{Reasons explaining the presence of body-gender taxonomies in visual representations}

Within the framework of the social construction of the body, 'the taxonomies applied to the perceived body (corpulent/thin, strong/weak) are, as always, simultaneously arbitrary and necessary, that is, founded on the specific reason of a certain social order' (Bourdieu, 1979, p. 215). With this in mind, we aimed to identify among the ECE teachers and ECE students the source of the body taxonomies related to gender in the images. These were: (a) the family and (b) the social context, especially the media.

Regarding the family, one teacher said:

This comes from really long ago and far away, and it's something that I for one try to eradicate. The problem is in homes, in families, and there are quite a few. They ask that their son not touch any dolls, any stroller, because it belongs to girls.-Teacher $\mathrm{K}$.

As far as the media goes, one student speculates:

Maybe the media with all these Disney films where, for example, all the girls want to be the princess from Frozen. I'm sure there are also some boys who want to be the Frozen princess, but they're afraid to say it, to be rejected or made fun of. - Student F.

In Bourdieu's (1987) words, 'le pouvour symbolique est un pouvoir de faire des choses avec des mots' (p. 164), or, 'symbolic power is the power to do things with words.' From these optics, the symbolic power of Disney's female images is embedded within a capitalist vision of consumerism, where the market takes advantage of the power of persuasion so that the descriptions of binary relationships land in the classroom through totalizing and globalizing messages. In this line, our research supports this notion but also adds new evidence of where in the ECE classrooms the heteronormativity and genders binaries are present: in the visual representations of children's bodies in curricular materials. So, as pointed out by Martínez-Bello and Martínez-Bello (2016), what can ECE teachers and students do about the different discourses swirling around the visual representations of the constructed body in the classrooms? The answer can only come from an emancipatory perspective in which 'both 
practices and their interpretations are questioned ... bolstering non-conformity and challenges to authorities' explanations ...' (Sánchez Blanco, 2000, p. 113).

\section{Sensitivity among ECE teacher and student teachers regarding gender issues}

As Sánchez Blanco (2000) saw it, the first step toward empowering the ECE teachers is framed within their recognition of their own sensitization to the issues that generate discrimination. For example:

That is, it's no good for a boy to tell me, 'I don't want to be in this baobob because it's pink.' So, I tell him I don't care if it's pink, green ... I want my students to think, to learn to think, to not just accept that I am the teacher and I say such a thing is one way, and that's the way it is. - Teacher $O$.

With regard to sensitization, another teacher decided to rework her own curricular materials based on a new critical perspective of her curricular practice:

Well, that this is a boy who's wearing a cap, and this is a girl who's wearing a bow ... If you take a closer look, you see that I took this out of ECE Teaching, and the image of the girl had hearts and the boy, balloons, and I refused ... why can't the boys have hearts? And so I made copies in which all of them had a picture with balloons and another picture with hearts.

We detected one element that differentiates the capacity for recognizing the stereotypes and modifying those patterns in the reconstruction of the materials: this is based primarily on the capacity for sensitization or, as one teacher said, 'if you haven't assimilated this problem ... you don't stop to think about it.' Nevertheless, the lived experiences of graduate students during their university training show them the positive, exemplary role that the teacher can play to fight against sexist stereotypes:

Classrooms have long worked to transmit that pink is not for boys, that blue is not for girls, and that all of the colors belong to everybody ... So I think it's more a question of families and the society ... I think that, especially my teacher, tried to fight against the [idea that] pink is for girls and blue is for boys. - Student A.

That is, teachers with experience in the classroom, who problematize the construction of meanings around gender in the ECE setting, become a reference for the future teachers learning about how to address this issue in their classrooms.

\section{Recognition of alternatives for combating body stereotypes}

The alternatives are based on two broad subcategories: treatment of conflicts with children and their families (a); and treatment of conflicts with their own interpretations (b). We understand 'treatment of conflict' according to Apple (2016), the process by which 'the hegemonic assumptions that ignore the real functioning of power in cultural and social life, and which signal the naturalness of acceptance, are put into relief' (p. 112). In this line, with respect to the treatment of conflict with children and families (a), one teacher says:

\footnotetext{
Perhaps if children are allowed to freely choose, they take on that role, but maybe in those cases you need to intervene, so the stereotype is not so pronounced, and above all so that it doesn't stay the same for the whole year ... I think in some cases it's necessary to intervene rather than allowing them so much freedom. Teacher $\mathrm{M}$.
}

These possibilities of choice maintain some common taxonomies in the case of Disney characters (see image \# 8). Although there is a wide range of choices (Snow White, Frozen, etc.), all of them reproduce the same distinctive features that reaffirm the common elements among all women.

As pointed out by Giroux (2004), before refusing to cover controversial themes in class, 'teachers should analyze the conflicts and contradictions as issues to be problematized and used as discussion points and as vehicles to connect classroom practices with broader political questions' (p. 253). One example of this is teachers' negotiation and treatment of conflict around the body-gender-stereotype relationship, recognizing that certain-often difficult-attitudes and barriers can be found in family environments. For example, one teacher signals: 
And it's true that we have encountered some parent who has said, 'Where are you going with all this? This is for girls,' and so then we say, 'No, no, excuse me, why is it for girls? It's pink ...' Things like that are what we most often come up against and what we have to fight the most. - Teacher $\mathrm{K}$.

Developing a critical attitude is not a linear or unidirectional process. Some teachers recognize that even though they can still fall into reproducing stereotypes, their capacity for self-criticism leads them to seek alternatives (b). One teacher notes:

Because it's hard, it's hard for all of us ... It was even hard for me to realize-we're so used to these gender differences that we don't even realize it. We're sending girls the message that they can't play, and telling boys that they can't be sensitive ... Why can't they have a heart? What happens-we make the boys homosexual because they take a heart when they're little? - Teacher J.

As Clarking-Phillips points out (2018), in the framework of ECE, teachers have the opportunity to provide explicit pedagogy in the form of prompts, support and provocations to enable them to take advantage of opportunities and contribute to the development of a secondary habitus. Just as Areljung and Kelly-Ware (2017) have studied power in terms of teachers' control over selecting and building on children's comments or actions, our research shows the desirability of ECE teachers reviewing both the content and images of their curricular materials carefully with an eye on gender equality prior to adopting a text. The goal should be to select images that challenge normative bodies and movement possibilities related with heteronormativity. In conclusion, in terms of social construction of the body, ECE teachers should navigate the risky terrain of non-normative, non-binary and diverse children's identities in the visual representations worked in their classrooms (Kelly, 2012; Morgan and Kelly-Ware, 2016).

\section{The role of training on gender equality}

With Connell (2005) in mind, who said, 'we cannot understand class, race or global inequality without constantly moving towards gender ... and gender politics are among the main determinants of our collective' (p. 76), one of the interview questions was about the education and training that both teachers and graduate students had received on gender equality over their lifetimes. The students recognized the role of teachers in their gender equality sensitivity training:

I think that this subject could be covered, not in a cross-sectional way but rather with greater depth. I think that as we can see in many classrooms, these problems exist, and I think that nowadays, future teachers could do it, not cross-sectionally but more in-depth. - Student B.

On the other hand, students and teachers recognized that the uptake of alternatives to the dominant models and discourses about what a girl or a boy is understood to be, or what an adult man or woman should be, has been a progressive, non-linear endeavor. It is constructed based on their own lived experiences and their interest in fostering respect for equality and lack of discrimination.

I think this comes from within oneself ... like, I mean from an education ... We bring to the classroom, regardless of whether you have university studies ... you bring a lot of concepts ... of what you have continued to study, of your family, and of yourself, a concept that you have created of yourself. - Teacher $O$.

Taking into account that boys and girls process knowledge and information that supports them to make sense of new experiences during their ongoing inquiries into their lives and worlds (KellyWare, 2016), and that in this process curricular materials transmit information about what it is like to be a girl or a boy, ECE teachers should be aware that the construction of their identity in the context of ECE is not neutral, but that 'certain ways of being, doing and saying become "truths" and are reinforced by peers, teachers and even absent parents and siblings' (Kelly-Ware, 2016, p. 149).

\section{Limitations and future research}

Our study is a first approximation of how ECE teachers recognize the social taxonomies in the visual representations of the children's body that allow them to classify bodies and their possibilities of 
action according to their notion of gender. Future research is necessary to explore how agency and habitus manifest in the faculty, through studies with participatory methodologies and approaches (participatory action research), for example studies that accompany the entire process of creation, implementation and evaluation of curricular materials, or that investigate how girls and boys negotiate the meanings of bodies in light of gender and sexuality in curricular materials.

\section{Conclusions}

This study critically analyzed the discourses that the ECE teachers and ECE students perceived in the visual representations present both in their ECE classrooms as well as in the selected sample images. Our results show that these images do not represent children as individuals, but rather as subjects with socially constructed labels that favor stereotypical roles from early childhood. For example, in the case of girls, their characteristics are those seen as dominant within a construct of femininity, while boys' characteristics are dominated by a construct of masculinity. For Bourdieu, the efficacy of symbolic power, that is, the power to classify and grant properties and signs to subjects, does not reside only in the power to impose, but also in the degree to which the vision is anchored within reality.

Based on Bourdieu's vision it is not so much a question of how teachers construct the body (from their habitus, capital) but in how they perceive the social representation of the body from the visual representations of the masculine and feminine bodies. In this research, the aim has been to use Bourdieu's theoretical heritage as a tool for recognizing the construction of difference between bodies in light of the images represented in the ECE classrooms. This vision can be contextualized in two ways.

First of all, teachers have the power of classification, in that they select, construct, and represent the bodies that ultimately arrive in ECE classrooms. This imposition should be understood as the position that teachers take when they reproduce manifestations of the social world that reflect the dominance of ideology in their curricular practices. From our analysis of the interviews, we observed that teachers relate their own education and training with the curricular practices they perform in their classrooms. So, it is logical that in some cases teachers find it difficult to recognize the bodygender relationship and to deal with the conflict and negotiation of the gender concept with families, colleagues, or themselves.

Secondly, the challenge of critically evaluating curricular practices related to the use, construction, creation, and recreation of curricular materials in ECE classrooms resides in the recognition of one's own ideologies and distortions is the first step toward unveiling the structures and practices of domination that oppress women and girls both within and outside the school system.

Finally, the students and ECE teachers recognize that the fight against taxonomies and labels with which the body is constructed is a process linked to the identity and autonomy of the agents who are participating in education, and this process has occurred cyclically throughout our history. That is, knowledge, sensitivity, and adoption of alternatives to the dominant discourses and models about what is understood to be a boy, a girl, a man, or a woman, is a gradual, non-linear process, constructed on the basis of one's own lived experiences and their interest in fostering respect for equality and lack of discrimination.

\section{Disclosure statement}

No potential conflict of interest was reported by the authors.

\section{References}

Apple, M. W. (2016). Ideologia y currículo. Madrid: Ediciones Akal, S.A.

Areljung, S., \& Kelly-Ware, J. (2017). Navigating the risky terrain of children's working theories. Early Years, 37(4), $370-385$. 
Barthes, R. (1977). The photographic message. In R. T. Craig \& H. L. Muller (Eds.), Image, music, text (pp. 15-31). New York: Sage.

Blaise, M. (2005). A feminist poststructuralist study of children "doing" gender in an urban kindergarten classroom. Early Childhood Research Quarterly, 20(1), 85-108.

Blanco García, N. e. I. A. d. I. M. (2000). El sexismo en los materiales educativos de la ESO. Sevilla: Instituto Andaluz de la Mujer.

Bourdieu, P. (1979). La distinction: critique sociale du jugement. Paris: Minuit.

Bourdieu, P. (1987). Choses dites. Paris: Les Éditions de Minuit.

Bourdieu, P. (1989). La noblesse de l'état. Paris: Ed. de Minuit.

Bourdieu, P. (1996). The state nobility: Elite schools in the field of power. Bloomington: Stanford University Press.

Bourdieu, P. (1998). La domination masculine. Paris: Éditions de Seuil.

Bourdieu, P., \& Wacquant, L. J. (1992). Réponses: Pour une anthropologie réflexive (p. 141). Paris: Seuil.

Brown, B. (1998). Unlearning discrimination in the early years. Staffordshire: Trentham Books Limited.

Butler, J. (1990). Gender trouble: Feminism and the subversion of identity. London: Routledge.

Clarkin-Phillips, J. (2018). Explicit pedagogy for transforming habitus: Early childhood teachers as mediators of affordances for parents. New Zealand Journal of Educational Studies, 53(1), 83-99.

Connell, R. W. (2005). Masculinities. 1995. Cambridge: Polity.

Fairclough, N. (2001). Language and power. Essex: Pearson Education.

Fairclough, N. (2003). Analysing discourse: Textual analysis for social research. London: Routledge.

García-Ochoa, Y. C., \& Martínez-Bello, V. (2014). "Libros para niñas y libros para niños": Presencia de estereotipos de género en una colección de libros para dibujar. Cuestiones de género: de la igualdad y la diferencia, 9, 182-215.

Garreta, N., \& Careaga, P. (1987). Modelos masculino y femenino en los textos de E.G.B. Madrid: Serie Estudios 14.

Giroux, H. (2004). Teoría y resistencia en educación. México: Siglo xxi editores.

Grundy, S. (1998). Producto o praxis del currículum. Madrid: Ediciones Morata.

Kelly-Ware, J. (2016). 'What's he doing that for? He'sa boy!': Exploring gender and sexualities in an early childhood setting. Global Studies of Childhood, 6(1), 147-154.

Kelly, J. (2012). Two daddy tigers and a baby tiger: Promoting understandings about same gender parented families using picture books. Early Years, 32(3), 288-300.

Mac Naughton, G. (2005). Doing Foucault in early childhood studies: Applying post-structural ideas. London: Routledge.

Martínez-Bello, V. E., \& Martínez-Bello, D. A. (2016). Depictions of human bodies in the illustrations of early childhood textbooks. Early Childhood Education Journal, 44(2), 181-190.

Martínez-Bello, V. E., \& Martínez-Bello, J. T. (2017). Bodies displayed on walls: Are children's bodies represented in an inclusive way in the pictures on the walls in their early childhood educational environments? Early Years, 37(2), 173-188.

Morgan, K., \& Kelly-Ware, J. (2016). "You have to start with something": Picture books to promote understandings of queer cultures, gender, and family diversity. Early Childhood Folio, 20(1), 3-8.

Rachlin, S. K., \& Vogt, G. L. (1974). Sex roles as presented to children by coloring books. Journal of Popular Culture, 8, 549556.

Rose, G. (2016). Visual methodologies: An introduction to researching with visual materials. London: SAGE.

Sánchez Blanco, C. (2000). De la Educación Infantil y su crítica: dilemas curriculares. Escolaridad temprana y discusión ideológica. Sevilla: MCEP.

Taylor, S. J., \& Bogdan, R. (1987). Introducción a los métodos cualitativos de investigación (Vol. 1). Barcelona: Paidós.

Varea, V., \& Pang, B. (2018). Using visual methodologies to understand pre-service health and physical education teachers' subjectivities of bodies. Sport, Education and Society, 23(5), 394-406.

Weitzman, L. J., Eifler, D., Hokada, E., \& Ross, C. (1972). Sex-role socialization in picture books for preschool children. American Journal of Sociology, 77(6), 1125-1150. 